\title{
A useful landmark to locate the external branch of the superior laryngeal nerve during thyroidectomy
}

\author{
Siu-Kwan Ng, Hok-Nam Li, Jason Ying-Kuen Chan, Eddy W. Y. Wong, Alexander C. Vlantis \\ Department of Otorhinolaryngology, Head and Neck Surgery, The Chinese University of Hong Kong, Prince of Wales Hospital, Shatin, N.T., \\ Hong Kong, China \\ Contributions: (I) Conception and design: SK Ng, HN Li; (II) Administrative support: SK Ng, HN Li; (III) Provision of study materials or patients: \\ All authors; (IV) Collection and assembly of data: All authors; (V) Data analysis and interpretation: SK Ng, JYK Chan; (VI) Manuscript writing: All \\ authors; (VII) Final approval of manuscript: All authors. \\ Correspondence to: Siu-Kwan Ng, FHKAM(Otorhinolaryngology). Department of Otorhinolaryngology, Head and Neck Surgery, The Chinese \\ University of Hong Kong, Prince of Wales Hospital, Shatin, N.T., Hong Kong, China. Email: ngsiukwan4@gmail.com.
}

Background To determine whether the insertion of the sternothyroid muscle onto the oblique line of the thyroid cartilage can be used to reliably locate the external branch of the superior laryngeal nerve (EBSLN) during thyroidectomy.

Methods: This is a prospective descriptive case series. The EBSLN was identified and confirmed with a nerve stimulator during thyroid surgery. The entry point of the EBSLN into the inferior constrictor/ cricothyroid muscle was measured in relation to the insertion and anterior border of the sternothyroid muscle. The perpendicular distance from the insertion of the sternothyroid muscle onto the oblique line was designated the vertical distance (VD) of the nerve entry point (NEP), and the perpendicular distance from the anterior border of the sternothyroid muscle was designated the horizontal distance.

Results: Ninety patients underwent 130 thyroid lobectomies (60 female, 30 male) (mean age 53.5 years, range, 18-91 years). An attempt to identify the nerve was made in 127 thyroid lobectomies. The EBSLN was identified in 111 cases (87.4\%). The mean VD of the NEP from the muscle insertion was $1.1 \mathrm{~mm}$ (SD 1.1 $\mathrm{mm}$, range, 0-5 $\mathrm{mm}$ ) and the mean horizontal distance (HD) was $9.5 \mathrm{~mm}$ (SD $3.8 \mathrm{~mm}$, range, 2-21 $\mathrm{mm}$ ).

Conclusions: The EBSLN muscle entry point usually lies $1.1 \mathrm{~mm}$ from the sternothyroid insertion onto the oblique line, and 5-12 $\mathrm{mm}$ from the anterior border of the muscle. These useful landmarks allow the nerve to be consistently located, identified and preserved during thyroid surgery prior to ligating the superior thyroid vessels.

Keywords: Laryngeal nerve; surgical landmark; thyroidectomy

Submitted Dec 12, 2019. Accepted for publication Feb 28, 2020.

doi: 10.21037 /gs.2020.03.25

View this article at: http://dx.doi.org/10.21037/gs.2020.03.25

\section{Introduction}

The external branch of the superior laryngeal nerve (EBSLN) innervates the cricothyroid muscle that controls the pitch of the voice. Injury to this nerve results in impaired voice projection, easy vocal fatigue and the inability to high-pitch phonate.

The EBSLN crosses the superior thyroid artery from lateral to medial, and where it does this forms the basis of the crossing types 1, 2A and 2B of Cernea et al. (1), that is, more than $1 \mathrm{~cm}$ above the upper border of the thyroid lobe, within $1 \mathrm{~cm}$ of the upper border of the thyroid lobe, or below the upper border of the thyroid lobe respectively.

Due to its close proximity to the superior thyroid vessels, its susceptibility to injury during thyroidectomy is well recognized. The traditional surgical technique involves ligating and dividing the superior thyroid vessels as close to the upper pole of the thyroid lobe as possible, 
without actually identifying the nerve, the nerve avoidance technique. Although this strategy remains mainstream, the risk of injury to the EBSLN is substantial as the nerve crosses close to or even below the upper border of the thyroid lobe in a significant portion of patients. Postthyroidectomy voice changes are not uncommon, despite apparent normal vocal cord mobility $(2,3)$. There is evidence that at least some cases of post-thyroidectomy dysphonia result from EBSLN injury. When laryngoscopy and voice analysis is used, the palsy rates range from $0 \%$ to $6 \%$ (4-7). When more accurate laryngeal electroneuromyography is included in the analysis, higher rates up to $58 \%$ are reported (8-12).

It is a general surgical principle to expose a nerve for its effective protection, such as the facial nerve in parotid surgery. This strategy has been the standard of care for the recurrent laryngeal nerve too. Using electromyography of the cricothyroid muscle as a post-operative outcome, prospective randomized studies have shown lower rates of EBSLN injury during thyroidectomy when the nerves were actively searched for and protected than when not $(13,14)$. Despite this, the reported rate of successful identification of the nerve varies greatly from one study to another, with identification rates ranging from $33 \%$ to $93 \%$ (15). One important reason for this variation is the lack of reliable surgical landmarks available to identify the EBSLN. The aim of this study was to investigate whether the sternothyroid muscle insertion onto the oblique line of the thyroid cartilage and the anterior border of the muscle can be used as a reliable reference to locate the nerve. A secondary aim was to determine the percentage distribution of Cernea types of the EBSLN crossing.

\section{Methods}

\section{Study design and patient eligibility}

Approval for the study, which was performed according to the Declaration of Helsinki, was obtained from the Joint Chinese University of Hong Kong - New Territories East Cluster Clinical Research Ethics Committee (CREC No. 2015.262) and informed written consent obtained from each patient.

This is a descriptive study of a prospective case series of open thyroidectomies performed in a tertiary referral hospital from February 2015 to July 2018. Adult patients who were scheduled for thyroidectomy were recruited if they consented to be enrolled. Exclusion criteria included previous same-side thyroid surgery, ipsilateral neck dissection, neck irradiation, or were scheduled to undergo thyroid isthmusectomy only.

\section{Surgery}

All patients underwent conventional open thyroidectomy under general anesthesia. After exposing the lobe, dissection started at the upper pole. The exposure of the upper pole of the thyroid lobe was enhanced by dividing the overlying anterior 1 to $1.5 \mathrm{~cm}$ of the sternothyroid muscle near its thyroid cartilage insertion. Retractors were then placed under the partially divided sternothyroid muscle which was retracted superiorly and laterally. The upper pole of the thyroid lobe was grasped with a Babcock forceps and pulled infero-laterally to open up the cricothyroid space of Reeves, which lies between the cricothyroid muscle medially and upper pole of the thyroid lobe laterally. This area was carefully dissected until the nerve was identified, and confirmed to be so with a nerve stimulator. After identification, the exposed nerve was followed until it entered into the inferior constrictor/cricothyroid muscle at the nerve entry point (NEP). The few small blood vessels that traverse the space can be differentiated from the nerve with a nerve stimulator and coagulated and divided. If the superior thyroid vessels are adequately dissected for safe ligation and division without identification of the EBSLN, the search for the nerve should be discontinued and the vessels ligated and divided as standard practice and the procedure continued.

\section{Outcome measurements}

The primary outcome is the anatomical relationship of the EBSLN entry point (NEP) into the inferior constrictor muscle and the insertion of the sternothyroid muscle onto the oblique line of the thyroid cartilage, which has been defined by two distances. The vertical distance (VD) is the perpendicular distance from the NEP to the sternothyroid insertion onto the oblique line of the thyroid cartilage. The horizontal distance (HD) is the distance from the NEP to the anterior border of the sternothyroid muscle, measured perpendicularly from the anterior end of the insertion of the muscle onto the oblique line of the thyroid (Figure 1).

A secondary outcome is the distribution of Cernea groupings of the nerve. The weight of the excised thyroid lobe was also recorded. 


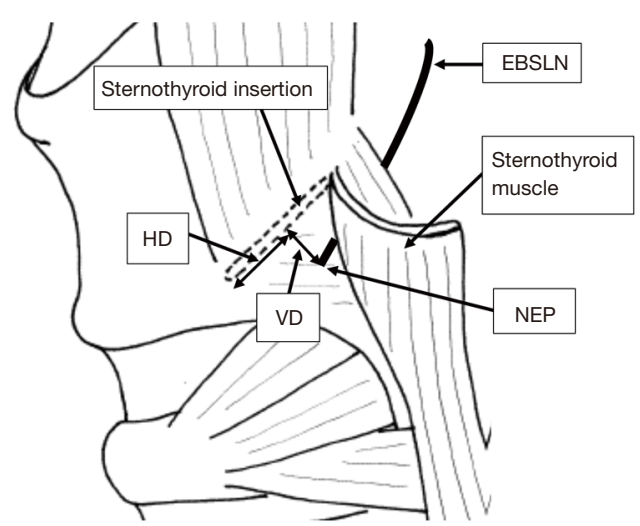

Figure 1 The distances from the sternothyroid insertion. HD, horizontal distance; VD, vertical distance; EBSLN, external branch of superior laryngeal nerve; NEP, nerve muscular entry point into the inferior constrictor/cricothyroid muscle.

Table 1 The indications for thyroid surgery

\begin{tabular}{lc}
\hline Diagnosis & Number of patients \\
\hline 1. Malignancy & 44 \\
2. Non-toxic solitary nodule & 14 \\
3. Non-toxic multinodular goiter & 23 \\
4. Toxic nodule/goiter/Graves' disease & 6 \\
5. Others & 3 \\
Total & 90 \\
\hline
\end{tabular}

\section{Results}

Ninety patients were recruited, 60 female and 30 male. Their mean age was 53.3 years (SD 15.3, range, 18-91). Fifty patients underwent hemithyroidectomy while 40 underwent total thyroidectomy, resulting in 130 lobectomies. Indications for surgery are listed in Table 1.

Dissection to look for the nerve was not done on three sides of the 130 sides (61 left and 69 right) due to tumor infiltration into the cricothyroid/inferior constrictor muscle. For the remaining 127 sides, the EBSLN was identified in 111 of them, giving a nerve identification rate of $87.4 \%$. On one of the sides, the sternothyroid muscle was absent and so the measurement of the VD and HD from the EBSLN muscle NEP could not be determined. For the rest, the mean VD was $1.1 \mathrm{~mm}$ (SD $1.1 \mathrm{~mm}$, range, $0-5 \mathrm{~mm}$ ) with over $90 \%$ occurring within the $0-2 \mathrm{~mm}$ range; the mean
HD was $9.5 \mathrm{~mm}$ (SD $3.8 \mathrm{~mm}$, range, $2-21 \mathrm{~mm}$ ) with over $80 \%$ occurring within the $5-12 \mathrm{~mm}$ range.

Of the 37 patients where bilateral surgery was done and nerve identification attempted, bilateral identification was achieved in 33 patients. Unilateral identification was achieved in three of these patients while in one patient the nerve could not be identified on either side.

Among the 111 EBSLNs identified, 9 were Cernea type 1, 44 were Cernea type 2A, and 58 were type 2B. The mean weight of an excised thyroid lobe was $42.9 \mathrm{~g}$ (SD $48.6 \mathrm{~g}$ range, 3 to $238 \mathrm{~g}$ ).

\section{Discussion}

The anatomical relationships of the EBSLN to neighboring structures has been extensively explored in the past, including with the carotid artery (16-18), the superior thyroid artery $(1,16,19,20)$, the inferior constrictor muscle of the pharynx $(4,16,21,22)$, and the ascending pharyngeal vein (23). Within this significant body of previous work on the surgical anatomy of the external branch of the superior laryngeal nerve, the findings were either too crude or too variable to be used as reliable surgical landmarks. The sternothyroid muscle inserts onto the oblique line of the lamina of the thyroid cartilage, which is a linear ridge between the superior and inferior thyroid tubercles. The advantages of using the sternothyroid insertion as a landmark include the fact that it does not vary with the direction and force of retraction during dissection, it is constant and easy to find, and its exposure does not require a wider area of dissection than that which is usually necessary for a thyroid lobectomy. Similarly, the EBSLN entry point into the muscle does not vary with the direction of pull on the lobe, nor is there a bothersome ligament or vessel nearby, compared to the entry site of recurrent laryngeal nerve. Once the NEP into the inferior constrictor/cricothyroid muscle has been found, the nerve can be readily traced superiorly.

From our results, the HD of the NEP from the anterior point of insertion of the sternothyroid muscle onto the oblique line is slightly variable, with over $80 \%$ of the NEP situated $5-12 \mathrm{~mm}$ from the anterior point of the sternothyroid insertion. On the other hand, the NEP consistently lies close to the sternothyroid muscle insertion onto the oblique line. Over $90 \%$ of the NEPs lie within 2 $\mathrm{mm}$ of the insertion and all within $5 \mathrm{~mm}$ from the insertion. Figure 2 shows the typical location of the NEP.

Interestingly, in one patient, there was a unilateral 


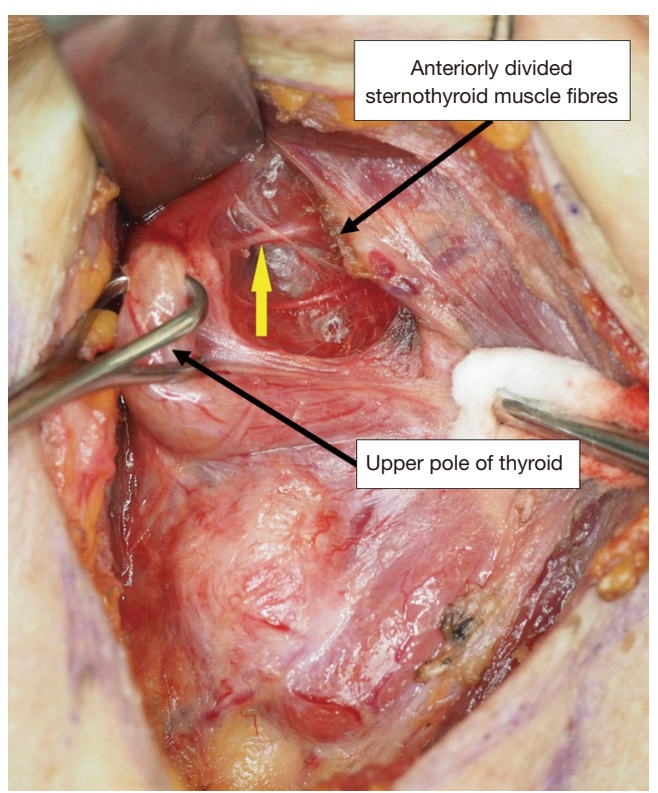

Figure 2 Right thyroidectomy. Dissection and retraction of the upper pole of the right thyroid lobe to reveal the external branch of the superior laryngeal nerve in the cricothyroid space of Reeves. Note the proximity of the nerve muscle insertion point to the sternothyroid insertion line. Arrow: external branch of superior laryngeal nerve.

absence of the sternothyroid muscle and hence these landmarks could not be used. Nevertheless, it is an exceedingly rare anomaly, with only a few cases reported in the literature (24-26).

In our exploration of the upper pole of the thyroid lobe, the anterior fibers of the sternothyroid muscle were routinely divided close to its insertion onto the oblique line. Such a maneuver does not result in adverse functional voice outcomes $(27,28)$. Instead, it greatly improved the exposure and ease of dissection of the EBSLN, thus reducing the chance of post-operative voice problems. In patients with large goiters, the complete division of the sternohyoid muscle was also necessary to expose the upper pole. Using a nerve stimulator, a rate of $87.4 \%$ successful identifications were possible in lobectomies in this series. For those nerves that could not be identified, it is possible that the nerve may have crossed the superior thyroid vessels higher up and were thus located superior to the area of dissection. The important point is to ensure that the upper pole vessel ligation and division is free of the EBSLN.

Our study showed a high prevalence of Cernea type 2 nerves $(91.9 \%)$ with $52.3 \%$ being type $2 \mathrm{~B}$ nerves. Even counting the unidentified nerves as type 1 nerves, assuming they were not identified because of a high crossing, the prevalence of type 2 and type $2 \mathrm{~B}$ nerves were $78.5 \%$ and $44.6 \%$ respectively, which is on the upper side of the range reported in the literature, where the rates of type 2 and type $2 \mathrm{~B}$ nerves were $37-83 \%$ and $11-40.8 \%$ respectively (1,20,29-33). A relatively high proportion of sizeable goiters in our series may account for this. This may be logical as a large goiter would tend to have a greater superior extension of the upper pole. Similar findings have also been reported in the literature (33-35).

\section{Conclusions}

This study showed that the EBSLN entry point into the inferior constrictor muscle usually lies within $2 \mathrm{~mm}$ from the sternothyroid muscle insertion onto the oblique line of the thyroid cartilage and $5-12 \mathrm{~mm}$ from the anterior border of the sternothyroid muscle, in the cricothyroid space of Reeves. With partial division of sternothyroid muscle fibers and using these landmarks, the EBSLN was successfully identified in $87.4 \%$ of 130 thyroid lobectomies in this series. The prevalence of Cernea type 2 EBSLNs, those most at risk of injury during thyroid lobectomy, is high especially in the presence of a large goiter. A routine identification approach is recommended to locate and protect the nerve, based on a sound understanding of local anatomy and described anatomical variations, and where possible to confirm it with a nerve stimulator, prior to ligating the superior thyroid vessels, to minimize the chance of inadvertent injury to the nerve.

\section{Acknowledgments}

Funding: None.

\section{Footnote}

Conflicts of Interest: All authors have completed the ICMJE uniform disclosure form (available at http://dx.doi. org/10.21037/gs.2020.03.25). The authors have no conflicts of interest to declare.

Ethical Statement: The authors are accountable for all aspects of the work in ensuring that questions related to the accuracy or integrity of any part of the work are appropriately investigated and resolved. Approval for the study, which was performed according to the Declaration of 
Helsinki, was obtained from the Joint Chinese University of Hong Kong - New Territories East Cluster Clinical Research Ethics Committee (CREC No. 2015.262) and informed written consent obtained from each patient.

Open Access Statement: This is an Open Access article distributed in accordance with the Creative Commons Attribution-NonCommercial-NoDerivs 4.0 International License (CC BY-NC-ND 4.0), which permits the noncommercial replication and distribution of the article with the strict proviso that no changes or edits are made and the original work is properly cited (including links to both the formal publication through the relevant DOI and the license). See: https://creativecommons.org/licenses/by-nc-nd/4.0/.

\section{References}

1. Cernea CR, Ferraz AR, Nishio S, et al. Surgical anatomy of the external branch of the superior laryngeal nerve. Head Neck 1992;14:380-3.

2. Stojadinovic A, Shaha AR, Orlikoff RF et al. Prospective functional voice assessment in patients undergoing thyroid surgery. Ann Surg 2002;236:823-32.

3. Soylu L, Ozbas S, Uslu HY, et al. The evaluation of the causes of subjective voice disturbances after thyroid surgery. Am J Surg 2007;194:317-22.

4. Lennquist $\mathrm{S}$, Cahlin C, Smeds S. The superior laryngeal nerve in thyroid surgery. Surgery 1987;102:999-1008.

5. Barczyński M, Konturek A, Stopa M, et al. Randomized controlled trial of visualization versus neuromonitoring of the external branch of the superior laryngeal nerve during thyroidectomy. World J Surg 2012;36:1340-7.

6. Jonas J, Bähr R. Neuromonitoring of the external branch of the superior laryngeal nerve during thyroid surgery. Am J Surg 2000;179:234-36.

7. Bellantone R, Boscherini M, Lombardi CP, et al. Is the identification of the external branch of the superior laryngeal nerve mandatory in thyroid operation? Results of a prospective randomized study. Surgery 2001;130:1055-9.

8. Jansson S, Tisell LE, Hagne I, et al. Partial superior laryngeal nerve (SLN) lesions before and after thyroid surgery. World J Surg 1988;12:522-7.

9. Barczyński M, Randolph GW, Cernea CR, et al. External branch of the superior laryngeal nerve monitoring during thyroid and parathyroid surgery: International Neural Monitoring Study Group standards guideline statement. Laryngoscope 2013;123 Suppl 4:S1-14.

10. Dionigi G, Kim HY, Randolph GW, et al. Prospective validation study of Cernea classification for predicting EMG alterations of the external branch of the superior laryngeal nerve. Surg Today 2016;46:785-91.

11. Uludag M, Aygun N, Kartal K, et al. Contribution of intraoperative neural monitoring to preservation of the external branch of the superior laryngeal nerve: a randomized prospective clinical trial. Langenbecks Arch Surg 2017;402:965-76.

12. Teitelbaum BJ, Wenig BL. Superior laryngeal nerve injury from thyroid surgery. Head Neck 1995;17:36-40.

13. Cernea CR, Ferraz AR, Furlani J, et al. Identification of the external branch of the superior laryngeal nerve during thyroidectomy. Am J Surg 1992;164:634-9.

14. Hurtado-López LM, Pacheco-Alvarez MI, MontesCastillo Mde L, et al. Importance of the intraoperative identification of the external branch of the superior laryngeal nerve during thyroidectomy: electromyographic evaluation. Thyroid 2005;15:449-54.

15. Shaaban A, Farouk A, Donia MM. External laryngeal nerve to identify or not during thyroidectomy: a singleinstitute experience. Egypt J Surg 2017;36:269-73.

16. Kambic V, Zargi M, Radsel Z. Topographic anatomy of the external branch of the superior laryngeal nerve. J Laryngol Otol 1984;98:1121-4.

17. Hill JH, Olson NR. The surgical anatomy of the spinal accessory nerve and the internal branch of the superior laryngeal nerve. Laryngoscope 1979;89:1935-42.

18. Furlan JC, Brandao LG, Ferraz AR. Surgical anatomy of the extralaryngeal aspect of the superior laryngeal nerve. Arch Otolaryngol Head Neck Surg 2003;129:79-82.

19. Cernea CR, Ferraz AR, Nishio S, et al. Identification of the external branch of the superior laryngeal nerve in large goiters. Am J Otolaryngol 1995;16:307-11.

20. Kierner AC, Ainger M, Burian M. The external branch of the superior laryngeal nerve: its topographical anatomy as related to surgery of the neck. Arch Otolaryngol Head Neck Surg 1998;124:301-3.

21. Lang J, Nachbaur S, Fischer K, et al. The superior laryngeal nerve and the superior laryngeal artery. Acta Anat 1987;130:309-18.

22. Friedman $M$, Losalvio P, Ibrahim H. Superior laryngeal nerve identification and preservation in thyroidectomy. Arch Otolaryngol Head Neck Surg 2002;128:296-303.

23. Ortega C, Maranillo E, McHanwell S, et al. External laryngeal nerve landmarks revisited. Head Neck 2018;40:1926-33.

24. Bale LSV, Herrin SO. Unilateral absence of the sternothyroid muscle: a case report. Int J Anat Var 
2016;9:55-6.

25. Walsham WJ. Anatomical Variations: An Account of a Few of the More Interesting Abnormalities that Have Occurred in the Dissecting-rooms During the Last Seven Years: with Remarks on Their Morphological Significance, and Their Bearing on the Practice of Surgery. St Bartholomew's Hospital Reports 1880;16:69-105.

26. Kampmeier OF. A striking case of asymmetry in the thyroid region associated with the occurrence of a branchial cyst. Anat Rec 1921;22:310-6.

27. Lee HS, Kim SW, Park HS, et al. Partial cutting of sternothyroid muscle during total thyroidectomy: impact on postoperative vocal outcomes. ScientificWorldJournal 2013;2013:416535.

28. Henry LR, Solomon NP, Howard R, et al. The Functional Impact on Voice of Sternothyroid Muscle Division During Thyroidectomy. Ann Surg Oncol 2008;15:2027-33.

29. Chuang FJ, Chen JY, Shyu JF, et al. Surgical anatomy of the external branch of the superior laryngeal nerve in Chinese Adults and its clinical applications. Head Neck 2010;32:53-7.

30. Ekhar VR, Ramkumar V, Shelkar RN, et al. Identification

Cite this article as: $\mathrm{Ng} \mathrm{SK}$, Li HN, Chan JYK, Wong EWY, Vlantis AC. A useful landmark to locate the external branch of the superior laryngeal nerve during thyroidectomy. Gland Surg 2020;9(3):647-652. doi: 10.21037/gs.2020.03.25 of external branch of superior laryngeal nerve during thyroid surgery: a prospective study. Int J Otorhinolaryngol Head Neck Surg 2018;4:228-32.

31. Furlan JC, Cordeiro AC, Brandao LG. Study of some "intrinsic risk factors" that can enhance an iatrogenic injury of the external branch of the superior laryngeal nerve. Otolaryngol Head Neck Surg 2003;128:396-400.

32. Seven H, Calis AB, Vural C. Microscopic thyroidectomy: a prospective controlled trial. Eur Arch Otorhinolaryngol 2005;262:41-4.

33. Aina EN, Hisham AN. External laryngeal nerve in thyroid surgery: recognition and surgical implications. ANZ J Surg 2001;71:212-4.

34. Ravikumar K, Sadacharan D, Muthukumar S, et al. EBSLN and factors influencing its identification and its safety in patients undergoing total thyroidectomy: A study of 456 cases. World J Surg 2016;40:545-50.

35. Menon RR, Murali S, Nair CG, et al. Correlation between the Cernea classification of external branch of superior laryngeal nerve in relation to the ultrasoundbased volume of thyroid gland. Indian J Endocrinol Metab 2017;21:845-7. 